\title{
Sistem Pakar Diagnosa Depresi Mahasiswa Akhir Dengan Metode Certainty Factor Berbasis Mobile
}

\author{
Apip Supiandi ${ }^{1}$, Damar Bagja Chandradimuka ${ }^{2}$ \\ ${ }^{1}$ STMIK Nusa Mandiri Sukabumi \\ e-mail: apip.aup@nusamandiri.ac.id \\ ${ }^{2}$ STMIK Nusa Mandiri Sukabumi \\ e-mail: damarbagjachandradimuka@gmail.com
}

\begin{abstract}
Abstrak
Tingkat depresi pada mahasiswa mengalami peningkatan dibandingkan usia anak-anak dan usia dewasa. Pada orang depresi cenderung tidak akan memperhatikan pola makan dan aktivitas fisiknya. Oleh sebab itu perlu adanya tindakan/penanganan secara dini untuk mencegah orang dewasa terjangkit depresi. Metode Certainty Factor merupakan metode yang mendefenisikan ukuran kepastian terhadap suatu fakta atau aturan, untuk menggambarkan tingkat keyakinan pakar terhadap masalah yang sedang dihadapi, dengan menggunakan Certainty Factor ini dapat menggambarkan tingkat keyakinan pakar. Untuk itu, dalam penelitian ini akan dilakukan analisa data tingkat depresi pada mahasiswa tingkat akhir menggunakan metode certainty factor. Dibutuhkan sebuah sistem yang dapat mewakili seorang pakar yang memiliki basis pengetahuan dan pengalaman tentang masalah depresi, yaitu sebuah sistem pakar. Teknologi berbasis mobile saat ini semakin pesat, yang mengakibatkan meningkatnya aplikasi-aplikasi mobile berbasis android. Oleh karena itu, agar mendapatkan nilai informasi yang lebih cepat dan fleksibel, sistem pakar ini akan diaplikasikan dalam bentuk aplikasi mobile berbasis Android sehingga dapat disimpulkan bahwa penelitian yang diimplementasikan ke dalam aplikasi android ini dapat membantu para pengguna khususnya para orang tua dalam mendiagnosa tingkat depresi pada mahasiswa tingkat akhir.
\end{abstract}

Kata Kunci: Sistem Pakar, Certainty Factor, Depresi, Aplikasi Mobile

\begin{abstract}
The rate of depression in students has increased compared to the age of children and adult age. In the depressed person tends not to pay attention to diet and physical activity. Therefore, the need for early action / treatment to prevent adults infected with depression. Certainty Factor method is a method that defines the size of certainty to a fact or rule, to describe the level of expert confidence to the problem at hand, using Certainty Factor can describe the level of expert confidence. For that, in this research will be analyzed data of depression level at student of final level using certainty factor method. It takes a system that can represent an expert who has a knowledge base and experience on the subject of depression, an expert system. Mobilebased technology is now growing rapidly, resulting in increased android-based mobile applications. Therefore, in order to get the value of information faster and flexible, this expert system will be applied in the form of Android-based mobile applications so it can be concluded that the research is implemented into this android application can help users, especially parents in diagnosing the level of depression in final-year students.
\end{abstract}

Keywords: Expert System, Certainty Factor, Depression, Mobile Applications 


\section{Pendahuluan}

Depresi adalah emosi yang datang ditengah ketidakberdayaan, kegagalan individu, dan datang saat individu berusaha untuk mendapatkankekuasaan yang belum dapat direalisasikan (Seligman,1993). Depresi adalah perasaan sedih, pesimis, dan merasa sendirian yang merupakan bagian dari depresi mayor dan gangguan masalah mood lainnya (Kaplan \& Sadock, 1996). Depresi adalah suatu perasaan kesedihan yang psikopatologis, disertai perasaan yang sedih, kehilangan minat dan kegembiraan, berkurangnya energi yang menuju kepada meningkatnya keadaan mudah lelah yang sangat nyata sesudah bekerja sedikit saja, dan berkurangnya aktivitas yang bisa jadi menandakan adanya gangguan kesehatan (Untari, 2005).

Tingkat depresi pada mahasiswa mengalami peningkatan dibandingkan usia anak-anak dan usia dewasa. Pada orang depresi cenderung tidak akan memperhatikan pola makan dan aktivitas fisiknya (Putra, 2016).

Pada praktik selama ini di dalam ilmu psikologi sebagian besar masih menggunakan cara-cara dan metode lama dalam proses memahami dan mempelajari sisi psikologis seorang manusia dengan segala sikap dan tingkah lakunya.Salah satu metode yang masih banyak digunakan dalam ilmu psikologi yakni dengan cara membuat quesioner atau serangkaian pertanyaan. Metode ini dirasa kurang efektif dan efisien karena masih dilakukan secara manual (Muhardi, 2014).

Kemudian untuk mempermudah melakukan diagnosa tingkat depresi pada mahasiswa tingkat akhir, maka dibutuhkan sebuah sistem yang dapat mewakili seorang pakar yang memiliki basis pengetahuan dan pengalaman. Sistem pakar merupakan program komputer yang meniru proses pemikiran dan pengetahuan pakar dalam menyelesaikan suatu masalah tertentu. Implementasi sistem pakar banyak digunakan dalam bidang kecerdasan buatan karena sistem pakar dipandang sebagai cara penyimpanan pengetahuan pakar pada bidang tertentu dalam program komputer sehingga keputusan dapat diberikan dalam melakukan penalaran secara cerdas (Veradani, 2014).

$$
\text { Metode Certainty }
$$

Factor merupakan metode yang mendefenisikan ukuran kepastian terhadap suatu fakta atau aturan, untuk menggambarkan tingkat keyakinan pakar terhadap masalah yang sedang dihadapi,dengan menggunakan Certainty Factor ini dapat menggambarkan tingkat keyakinan pakar (Sari, 2013).

Sistem pakar akan lebih berfungsi ketika dipadukan dengan kemajuan teknologi, salah satunya yaitu android. Androidadalah sebuah sistem operasi untuk perangkat mobile berbasis linux yang mencakup sistem operasi, middle-ware, dan aplikasi. Android menyediakan platform terbuka bagi para pengembang untuk menciptakan aplikasi mereka (Anggraini, 2014).

\section{Metode Penelitian Certainty Factor}

Metode certainty factor digunakan ketika menghadapi suatu masalah yang jawabannya tidak pasti. Ketidakpastian ini bisa merupakan probabilitas. Metode ini diperkenalkan oleh Shortlife Buchanan pada tahun 1970-an. Beliau menggunakan metode ini saat melakukan diagnosis dan terapi terhadap penyakit meningitis dan infeksi darah (Daniel, 2010). Tim pengembang dari metode ini mencatat bahwa, dokter sering kali menganalisa informasi yang ada dengan ungkapan seperti "mungkin", "hampir pasti". Metode ini mirip dengan fuzzy logic, karena ketidakpastian direpresentasikan dengan derajat kepercayaan sedangkan perbedaannya adalah pada fuzzy logic saat perhitungan untuk rule yang premisnya lebih dari satu, fuzzy logic tidak memiliki nilai keyakinan untuk rule tersebut sehingga perhitungannya hanya melihat nilai terkecil untukoperator AND atau nilai terbesar untuk operator OR dari setiap premis yang pada rule tersebut berbeda dengan certainty factor yaitu setiap rule memiiki nilai keyakinannya sendiri tidak hanya premis-premisnya saja yang memiliki nilai keyakinan. Certainty factor menunjukkan ukuran kepastian terhadap suatu fakta atau aturan (Daniel, 2010).

Keterangan :

$$
C F[h, e]=M B[h, e]-M D[h, e]
$$

$\mathrm{CF}[\mathrm{h}, \mathrm{e}]=$ faktor kepastian

$\mathrm{MB}[\mathrm{h}, \mathrm{e}]=$ measure of belief, ukuran kepercayaan atau tingkat keyakinan terhadap hipotesis (h), jika diberikan evidence (e) antara 0 dan 1

$\mathrm{MD}[\mathrm{h}, \mathrm{e}]=$ measure of disbelief, ukuran ketidakpercayaan atau tingkat 
keyakinan terhadap hipotesis (h), jika diberikan evidence (e) antara 0 dan 1.

Adapun beberapa kombinasi certainty factor terhadap premis tertentu:

1. Certainty factor dengan satu premis.

$\mathrm{CF}[\mathrm{h}, \mathrm{e}]=\mathrm{CF}[\mathrm{e}]{ }^{*} \mathrm{CF}[\mathrm{rule}]$

$$
=\mathrm{CF}[\text { user] * } \mathrm{CF} \text { [pakar] }
$$

2. Certainty factor dengan lebih dari satu premis.

$\mathrm{CF}[\mathrm{A} \wedge \mathrm{B}]=\operatorname{Min}(\mathrm{CF}[\mathrm{a}], \mathrm{CF}[\mathrm{b}]){ }^{*} \mathrm{CF}[$ rule $]$ $\mathrm{CF}[\mathrm{A} \vee \mathrm{B}]=\operatorname{Max}(\mathrm{CF}[\mathrm{a}], \mathrm{CF}[\mathrm{b}]){ }^{*} \mathrm{CF}[$ rule $]$

3. Certainty factor dengan kesimpulan yang serupa.

CFgabungan[CF1, CF2] $=\mathrm{CF} 1+\mathrm{CF} 2$ * $(1-\mathrm{CF} 1)$

Kelebihan dari metode ini adalah cocok digunakan pada sistem pakar yang mengukur sesuatu yang pasti atau tidak pasti seperti mendiagnosis penyakit dan perhitungan dari metode ini hanya berlaku untuk sekali hitung, serta hanya dapat mengolah dua data sehingga keakuratannya terjaga (Turban, 2001).

\section{Teknik Pengumpulan Data}

\section{A. Observasi}

Dalam penyusunan skripsi ini, dilakukan pengamatan langsung/observasi dengan mengumpulkan beberapa data depresi mahasiswa tingkat akhir.

B. Wawancara

Selain observasi, dilakukan juga wawancara langsung terhadap para pakar yang memiliki pengetahuan khusus tentang depresi mahasiswa tingkat akhir.

C. Studi Pustaka

Pada metode ini, dilakukan pencarian dan pembelajaran dari berbagai macam literatur dan dokumen yang menunjang pengerjaan penelitian ini, diantaranya dari buku, artikel ilmiah, juga dari berbagai macam website internet yang menyediakan informasi yang relevan dengan permasalahan dalam sistem pakar ini.

\section{Hasil dan Pembahasan}

Untuk memenuhi syarat-syarat pada aplikasi sistem pakar untuk penetuan tingkat depresi pada mahasiswa tingkat akhir dengan menggunakan metode Certainty Factor yaitu suatu metode dimana sistem pakar (misalnya psikolog) sering menganalisis informasi yang ada dengan ungkapan seperti "mungkin", "kemungkinan besar", "hampir pasti", untuk mengakomodasi hal ini digunakan Certainty Factor guna menggambarkan tingkat keyakinan pakar terhadap masalah yang sedang dihadapi.

\subsection{Pengembangan Software}

A. Analisa Kebutuhan Sistem

Dari beberapa perangkat teknologi yang ada, program sistem pakar depresi pada mahasiswa tingkat akhir ini akan diaplikasikan pada perangkat mobile yang bersistem operasi android, karena sistem operasi android semakin populer dan semakin banyak penggunanya..

B. Desain

Dikarenakan program ini akan diterapkan dalam sistem operasi Android, maka proses desain interface dari program sistem pakar ini menggunakan Eclipse yang ditambahkan dengan SDK (Software Developmnet Kit) Android, ADT (Android Developmnet ) Tool).

C. Testing

Teknik pengujian yang paling sesuai untuk menguji sistem pakar yakni dengan menggunakan teknik black box testing. Karena merupakan pendekatan yang melengkapi untuk menemukan kesalahan lainnya.

D. Implementasi

Untuk melakukan kegiatan spesifikasi rancangan logika ke dalam kegiatan yang sebenarnya dari sistem pakar yang akan dibangun atau dikembangkan, lalu mengimplementasikan sistem yang baru tersebut kedalam salah satu bahasa pemograman yang berbasis mobile computing.

\subsection{Analisa Tingkat Depresi}

Sebelum merancang dan mengusulkan sebuah sistem pakar mengenai gejala-gejala depresi, penulis perlu mengetahui analisis terhadap mahasiswa dengan cara memberikan beberapa pertanyaan untuk mengetahui tingkat depresi mahasiswa semester akhir (Lubis, 2009). Adapun dengan pertanyaan tersebut kemudian penulis menentukan gejala tingkat depresi yang dialami mahasiswa semester akhir. Tingkat depresi pada mahasiswa semester akhir dibagi atas beberapa kriteria yaitu:

1. Mild depression/minor depression dan dysthymic disorder. Pada depresi ringan, mood yang rendah datang dan pergi dan penyakit datang setelah kejadian stressfull yang spesifik. Individu akan merasa cemas dan juga tidak bersemangat. Perubahan gaya hidup biasanya dibutuhkan untuk mengurangi depersi jenis ini. Minor depression 
ditandai dengan adanya dua gejala pada depressive episode namun tidak lebih dari lima gejala depresi muncul selama dua minggu berturut-turut, dan gejala itu bukan karena pengaruh obatan-obatan atau penyakit. Bentuk depresi yang kurang parah disebut distimia (Dystymic disorder). Depresi ini menimbulkan gangguan Minor Depression ringan dalam jangka waktu yang lama sehingga seseorang tidak dapat bekerja optimal. Gejala depresi ringan ada gangguan distimia dirasakan minimal dalam jangka waktu dua tahun.

2. Moderate Depression. Pada depresi sedang mood yang rendah berlangsung terus dan individu mengalami simtom fisik juga walaupun berbeda-beda tiap individu. Perubahan gaya hidup saja tidak cukup dan bantuan diperlukan untuk mengatasinya.

3. Severe depression/major depression. Depresi berat adalah penyakit yang tingkat depresinya parah. Individu akan mengalami gangguan dalam kemampuan untuk bekerja, tidur, makan, dan menikmati hal yang menyenangkan dan penting untuk mendapatkan bantuan medis secepat mungkin. Deperesi ini dapat muncul sekali atau dua kali dan beberapa kali selama hidup. Major depression ditandai dengan adanya lima atau lebih simtom yang ditunjukan dalam major depressive episode dan berlangsung selama dua minggu berturut-turut.

Adapun gejala pada tingkat depresi adalah sebagai berikut:

1. Kesedihan

2. Pesimis

3. Kegagalan

4. Kehilangan Kenikmatan

5. Perasaan Bersalah

6. Perasaan di hukum

7. Pikiran Bunuh Diri

8. Gelisah

9. Kehilangan Ketertarikan

10. Keraguan

11. Kehilangan Energi

12. Perubahan Pola Tidur

13. Perubahan Nafsu Makan

14. Sulit Konsentrasi

15. Kelelahan.

Berdasarkan informasi tersebut

maka pada kasus ini disusun kaidah produksi atau rulebase yang berkaitan dengan tingkat Depresi mahasiswa semester akhir, kaidah-kaidah adalah sebagaiberikut:

Adapun logika perubahan masingmasing memiliki bobot adalah sebagai berikut:

1. Tidak Yakin $=0$

2. Tidak Tahu $=0,2$

3. Sedikit Yakin $=0,4$

4. Cukup Yakin $=0,6$

5. Yakin $=0,8$

6. Sangat Yakin $=1$

7. Mungkin Tidak $=-0,4$

Nilai 0 menunjukkan bahwa pengguna konsultasi mengkonfirmasikan bahwa seseorang tersebut tidak memiliki tingkat depresi seperti ditanyakan oleh sistem. Semakin pengguna konsultasi yakin pada tingkat depresi tersebut, maka semakin tinggi pula hasil persentase keyakinan yang diperoleh. Proses perhitungan persentase keyakinan diawali dengan pemecahan sebuah kaidah yang memiliki premis tunggal. Kemudian masing-masing-aturan baru dihitung Certainty Factor nya, sehingga diperoleh nilai Certainty Factor untuk masing-masing aturan, kemudian nilai Certainty Factor tersebut dikombinasi.

Untuk mengasumsikan tingkat kepastian seorang pakar terhadap suatu data, maka konsep ini kemudian diformulasikan dalam rumusan dasar sebagai berikut:

$\mathrm{CF}[\mathrm{H}, \mathrm{E}]=\mathrm{MB}[\mathrm{H}, \mathrm{E}]-\mathrm{MD}[\mathrm{H}, \mathrm{E}]$

$\mathrm{CF}[\mathrm{H}, \mathrm{E}] 1=\mathrm{CF}[\mathrm{H}]^{*} \mathrm{CF}[\mathrm{E}]$

CFcombineCF[H,E]1,2 =

$\mathrm{CF}[\mathrm{H}, \mathrm{E}] 1+\mathrm{CF}[\mathrm{H}, \mathrm{E}] 2^{*}[1-\mathrm{CF}[\mathrm{H}, \mathrm{E}] 1]$

Cfcombine CF[H,E]old3 = CF[H,E]old +

$\mathrm{CF}[\mathrm{H}, \mathrm{E}] 3^{*}[1-\mathrm{CF}[\mathrm{H}, \mathrm{E}] \mathrm{old}]$

Adapun rule untuk tingkat depresi mahasiswa semester akhir adalah sebagai berikut:

IF D2 And D13

Then M1

IF D1 AND D3

AND D5

AND D6

AND D8

AND D10

AND D11

AND D12

AND D14

AND D15

THEN M2

IF D4 AND D7

AND D9

THEN M3 
Langkah awal pakar menentukan CF untuk masing-masing gejala sebagai berikut:
D1pakar $=1,0$
D2 pakar $=0,2$
D3 pakar $=0,8$
D4 pakar $=0,5$
D5 pakar $=0,4$
D6 pakar $=0,3$
D7 pakar $=0,8$
D8 pakar $=0,8$
D9 pakar $=1,0$
D10 pakar $=1,0$
D11 pakar $=0,3$
D12 pakar $=0,8$
D13 pakar $=1,0$
D14 pakar $=0,4$
D15 pakar $=0,2$

Misalkan user memilih jawaban sebagai berikut:

D1 = Tidak tahu $=0,2$

D2 $=$ Sedikit yakin $=0,4$

D3 $=$ Sangat yakin $=1$

D4 = Sangat yakin $=1$

$\mathrm{D} 5=$ Sedikit yakin $=0,4$

D6 $=$ Yakin $=0,8$

$\mathrm{D} 7=$ Sangat yakin $=1$

D8 $=$ Tidak yakin $=0$

D9 $=$ Sangat yakin $=1$

D10 $=$ Sedikit yakin $=0,4$

$\mathrm{D} 11=$ Tidak tahu $=0,2$

$\mathrm{D} 12=$ Tidak tahu $=0,2$

D13 $=$ Sedikit yakin $=0,4$

D14 $=$ Mungkin tidak $=-0,4$

D15 $=$ Sedikit yakin $=0,4$

Kaedah tersebut dihitung nilai Cfnya dengan mengalikan dengan Cfuser dengan Cfpakar menjadi :

$\mathrm{CF}[\mathrm{H}, \mathrm{E}] 1=\mathrm{CF}[\mathrm{H}] 1^{*} \mathrm{CF}[\mathrm{E}] 1$

$$
\begin{aligned}
& =1,0 * 0,2 \\
& =0,2
\end{aligned}
$$

$\mathrm{CF}[\mathrm{H}, \mathrm{E}] 2=\mathrm{CF}[\mathrm{H}] 2^{*} \mathrm{CF}[\mathrm{E}] 2$

$$
=0,2 * 0,4
$$

$$
=0,8
$$

$\mathrm{CF}[\mathrm{H}, \mathrm{E}] 3=\mathrm{CF}[\mathrm{H}] 3^{*} \mathrm{CF}[\mathrm{E}] 3$

$$
=0,8 * 1
$$

$$
=0,8
$$

$\mathrm{CF}[\mathrm{H}, \mathrm{E}] 4=\mathrm{CF}[\mathrm{H}] 4^{*} \mathrm{CF}[\mathrm{E}] 4$

$$
=0,5 * 1
$$

$$
=0,5
$$

$\mathrm{CF}[\mathrm{H}, \mathrm{E}] 5=\mathrm{CF}[\mathrm{H}] 5^{\star} \mathrm{CF}[\mathrm{E}] 5$

$$
=0,4{ }^{*} 0,4
$$

$$
=0,16
$$

$\mathrm{CF}[\mathrm{H}, \mathrm{E}] 6=\mathrm{CF}[\mathrm{H}] 6^{*} \mathrm{CF}[\mathrm{E}] 6$

$$
=0,3^{*} 0,8
$$

$$
=0,24
$$

$\mathrm{CF}[\mathrm{H}, \mathrm{E}] 7=\mathrm{CF}[\mathrm{H}] 7^{*} \mathrm{CF}[\mathrm{E}] 7$

$$
=0,8 * 1
$$

$$
=0,8
$$

$\mathrm{CF}[\mathrm{H}, \mathrm{E}] \mathrm{8}=\mathrm{CF}[\mathrm{H}] 8^{*} \mathrm{CF}[\mathrm{E}] 8$

$$
=0,8 * 0
$$

$$
=0
$$

$\mathrm{CF}[\mathrm{H}, \mathrm{E}] 9=\mathrm{CF}[\mathrm{H}] 9^{*} \mathrm{CF}[\mathrm{E}] 9$

$$
=1,0 * 1
$$$$
=1
$$

$\mathrm{CF}[\mathrm{H}, \mathrm{E}] 10=\mathrm{CF}[\mathrm{H}] 10^{*} \mathrm{CF}[\mathrm{E}] 10$

$$
\begin{aligned}
& =1,0 * 0,4 \\
& =0,4
\end{aligned}
$$

$\mathrm{CF}[\mathrm{H}, \mathrm{E}] 11=\mathrm{CF}[\mathrm{H}] 11^{*} \mathrm{CF}[\mathrm{E}] 11$

$$
\begin{aligned}
& =0,3 * 0,2 \\
& =0,6
\end{aligned}
$$

$\mathrm{CF}[\mathrm{H}, \mathrm{E}] 12=\mathrm{CF}[\mathrm{H}] 12^{*} \mathrm{CF}[\mathrm{E}] 12$

$$
\begin{aligned}
& =0,8 * 0,2 \\
& =0,16
\end{aligned}
$$

$\mathrm{CF}[\mathrm{H}, \mathrm{E}] 13=\mathrm{CF}[\mathrm{H}] 13^{*} \mathrm{CF}[\mathrm{E}] 13$

$$
\begin{aligned}
& =1,0 * 0,4 \\
& =0,4
\end{aligned}
$$

$\mathrm{CF}[\mathrm{H}, \mathrm{E}] 14=\mathrm{CF}[\mathrm{H}] 14^{*} \mathrm{CF}[\mathrm{E}] 14$

$$
\begin{aligned}
& =0,4 *-0,4 \\
& =-0,16
\end{aligned}
$$

$\mathrm{CF}[\mathrm{H}, \mathrm{E}] 15=\mathrm{CF}[\mathrm{H}] 15^{*} \mathrm{CF}[\mathrm{E}] 15$

$$
\begin{aligned}
& =0,2 * 0,4 \\
& =0,8
\end{aligned}
$$

Input:

D1, D2, D3, D4, D5, D6, D7, D8, D9, D10, D11,D12, D13, D14, D15

Output:

IF D1 CF[H,E $11=\mathrm{CF}[\mathrm{H}] 1{ }^{*} \mathrm{CF}[\mathrm{E}] 1$

$$
\begin{aligned}
& =1,0 * 0,2 \text { THEN } \\
& =0,2
\end{aligned}
$$

IF D2 CF $[\mathrm{H}, \mathrm{E}] 2=\mathrm{CF}[\mathrm{H}] 2^{*} \mathrm{CF}[\mathrm{E}] 2$

$$
\begin{aligned}
& =0,2{ }^{*} 0,4 \text { THEN } \\
& =0,8
\end{aligned}
$$

IF D3 $\mathrm{CF}[\mathrm{H}, \mathrm{E}] 3=\mathrm{CF}[\mathrm{H}] 3^{*} \mathrm{CF}[\mathrm{E}] 3$

$$
\begin{aligned}
& =0,8^{*} 1 \text { THEN } \\
& =0,8
\end{aligned}
$$

IF D4 CF[H,E]4 = CF[H] $4{ }^{*} \mathrm{CF}[\mathrm{E}] 4$

$$
=0,5 * 1 \text { THEN }
$$

$=0,5$

IF D5 CF $[\mathrm{H}, \mathrm{E}] 5=\mathrm{CF}[\mathrm{H}] 5^{\star} \mathrm{CF}[\mathrm{E}] 5$

$$
=0,4 * 0,4 \text { THEN }
$$

$$
=0,16
$$

IF D6 CF $[\mathrm{H}, \mathrm{E}] 6=\mathrm{CF}[\mathrm{H}] 6^{\star} \mathrm{CF}[\mathrm{E}] 6$

$$
=0,3 * 0,8 \text { THEN }
$$

$$
=0,24
$$

IF D7 CF[H,E]7 $=\mathrm{CF}[\mathrm{H}] 7^{\star} \mathrm{CF}[\mathrm{E}] 7$ $=0,8 * 1$ THEN

$$
=0,8
$$

IF D8 CF $[\mathrm{H}, \mathrm{E}] 8=\mathrm{CF}[\mathrm{H}] 8^{*} \mathrm{CF}[\mathrm{E}] 8$

$$
=0,8 * 0 \text { THEN }
$$

$=0$

IF D9 CF[H,E]9 $=\mathrm{CF}[\mathrm{H}] 9^{*} \mathrm{CF}[\mathrm{E}] 9$

$$
=1,0 * 1 \text { THEN }
$$$$
=1
$$ 
IF D10 CF[H,E]10 $=\mathrm{CF}[\mathrm{H}] 10^{*} \mathrm{CF}[\mathrm{E}] 10$ $=1,0 * 0,4$ THEN $=0,4$

IF D11 CF $[\mathrm{H}, \mathrm{E}] 11=\mathrm{CF}[\mathrm{H}] 11^{\star} \mathrm{CF}[\mathrm{E}] 11$ $=0,3{ }^{*} 0,2 \mathrm{THEN}$ $=0,6$

IF D12 CF $[\mathrm{H}, \mathrm{E}] 12=\mathrm{CF}[\mathrm{H}] 12^{*} \mathrm{CF}[\mathrm{E}] 12$ $=0,8 * 0,2$ THEN $=0,16$

IF D13 CF[H,E $] 13=\mathrm{CF}[\mathrm{H}] 13^{*} \mathrm{CF}[\mathrm{E}] 13$ $=1,0 * 0,4$ THEN $=0,4$

IF D14 CF[H,E]14 = CF $[\mathrm{H}] 14^{*} \mathrm{CF}[\mathrm{E}] 14$ $=0,4^{*}-0,4$ THEN $=-0,16$

IF D15 CF $[\mathrm{H}, \mathrm{E}] 15=\mathrm{CF}[\mathrm{H}] 15^{\star} \mathrm{CF}[\mathrm{E}] 15$ $=0,2{ }^{*} 0,4 \mathrm{THEN}$ $=0,8$

END.

Proses:

IF D1 THEN $S=$ Cobalah untuk menyadari bahwa semua orang pada saat yang berbeda juga mengalami hal yang sama seperti Anda rasakan. Yakinkan diri, cepat atau lambat kesedihan ini akan berakhir.

IF D2 THEN $S=$ Saat keyakinan sudah mantap dalam hati, maka dia akan begitu semangat dalam berikhtiar, optimis, dan menyongsong masa depan yang lebih baik. Masa lalu boleh kelabu. Saat ini mungkin banyak masalah. Tetapi, tidak ada alasan kalau besok akan tetap seperti ini.

IF D3 THEN S= Bersyukurlah jika anda mengalami kegagalan atau kemalangan. Karena dengan kegagalan anda sedang disiapkan untuk meraih kesuksesan yang lebih besar. Anda akan ditempa untuk menjadi lebih kuat dari sebelumnya.

IF D4 THEN S= Mencobalah untuk membuka diri dan menerima masukan dari orang lain, tujuan nya agar kita tidak selalu terdiam karena terpikir sutu masalah.

IF D5 THEN S= Perasaan bersalah muncul karena merasa Tertekan karena Berbagai Kewajiban Dalam penyusunan skripsi, dengan ini cobalah anda untuk mencoba dan berpikir positif dan terus mencoba.

IF D6 THEN S= Perasaan dihukum muncul karena berawalkan dari kegagalan yang pernah anda alami secara terus menerus, untuk menetralisir itu perlu adanya dukungan dari orang lain, berusahalah terus karena sejatinya itu adalah ujian hidup yang harus anda lewati.
IF D7 THEN $S=$ Gunakan kesadaran Anda sebagai manusia utuh. Daripada memikirkan masalah atau pemecahannya, lebih baik kita bergerak ke jalan yang baru: jangan pikirkan masalah itu dulu. Dengan menggunakan kesadaran yang kita miliki, kita harus mengabaikan pikiran yang mengatakan bahwa situasi yang sedang kita hadapi itu sangat 'complicated'. Ingat bahwa pikiran bukanlah diri kita yang sebenarnya. Dengan prinsip ini, gunakanlah kesadaran kita yang sepenuhnya sebagai ciptaan Allah yang utuh Intinya, kesadaran Anda harus mampu mengatakan, "Ini dapat diatasi".

IF D8 THEN S=Tantangan, pada hakikatnya bukan untuk dihindari, melainkan justru untuk dilakoni. Hidup itu sendiri adalah tantangan, adalah masalah. Mengapa kita mesti menghindar? Di sinilah kadang-kadang kita lupa pada kesejatian diri. Selalu berusaha dan katakan dalam hati ini pasti berahir dengan.

IF D9 THEN $S=$ Jangan selalu terdiam karena masalah yang ini, masih banyak yang harus anda lakukan cobalah bangkit "anda masih di tunggu" bangkitlah sekarang!!

IF D10 THEN S=Sebetulnya, semangat yang kuat itu diperlukan untuk mengatasi semua

keraguan dan cobaan yang bisa mematikan kesungguhannya untuk mencapai hal-hal penting atau besar yang diinginkannya.

IF D11 THEN S=Yang pasti, setiap masalah yang nyata, pasti ada pemecahannya, dan tentu saja setiap usaha pasti ada hasilnya. Asal Anda tahu apa yang harus dilakukan, dan kenapa masalah itu terjadi, pemecahan sudah ada di tangan. Anda tinggal menggerakkan diri, perangi segala kemalasan yang membawa kerugian itu.

IF D12 THEN S= Susah tidur atau Insomnia adalah paduan dari gejala dan akibat dari depresi dan kegelisahan. Karena otak menggunakan 'sinyal' serupa untuk mengatur jadwal tidur dan emosi, sangat sulit untuk menentukan mana yang harus dimunculkan lebih dulu.

IF D13 THEN S=Pikirkan bagaimana rasa malas ini mempengaruhi kualitas hidup Anda, hubungan Anda, membuat Anda kehilangan kesempatan, kesehatan dan energi yang memburuk. Lalu buat daftar apa saja yang dapat Anda lakukan . Jangan biarkan diri anda 
tersikasa, anda masih dibutuhkan banyak orang.

IF D14 THEN $S=$ =Anda harus belajar untuk mendorong diri sendiri untuk membatasi. Jika Anda menemukan konsentrasi Anda, lakukan trik sederhana tapi manjur ini. Ambillah nafas dalam-dalam dan perlahan. Ketika Anda mengambil nafas seperti itu, seketika itu juga otak Anda terstimulasi masuk pada frekwensi Low beta.

IF D15 THEN S=Kelelahan anda muncul disebabkan karena pikiran anda yang lelah untuk memikirkan masalah ini. Jadi, cobalah untuk menenangankan diri dangan istirahat atau dengan mencari tempat yang bisa membuat anda tenang untuk sementara waktu.

\subsection{Implentasi}

\section{Analisa Kebutuhan Software}

A. Use Case Diagram

Deskripsi Use Case Diagram Diagnosa Tingkat Depresi :

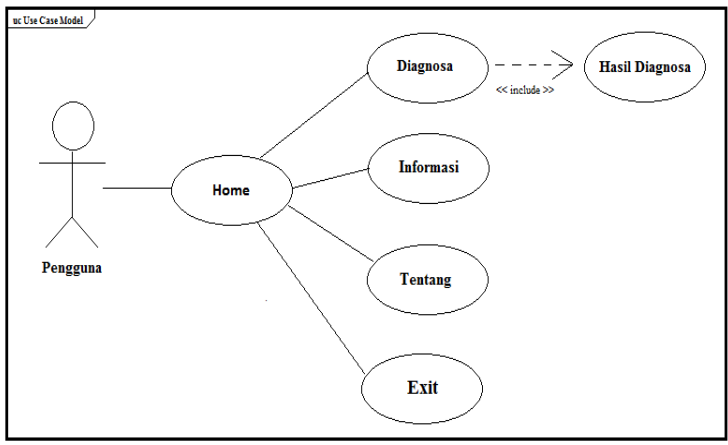

Gambar 1.

Use Case Diagram DiagnosaTingkat Depresi

Tabel 1. Deskripsi Use Case Diagram Menu Diagnosa

\begin{tabular}{|l|l|}
\hline Use Case Name & Menu Diagnosa \\
\hline Requirment & A1 \\
\hline Goal & $\begin{array}{l}\text { Pengguna } \\
\text { mendapatkan hasil } \\
\text { diagnosa }\end{array}$ \\
\hline Pre-condition & $\begin{array}{l}\text { Pengguna memilih } \\
\text { menu diagnosa }\end{array}$ \\
\hline Post-condition & Tampil hasil diagnosa \\
\hline $\begin{array}{l}\text { Failed end } \\
\text { condition }\end{array}$ & $\begin{array}{l}\text { Pengguna tidak } \\
\text { memilih menu } \\
\text { diagnosa }\end{array}$ \\
\hline Primary Actor & Pengguna \\
\hline $\begin{array}{l}\text { Main Flow/Basic } \\
\text { Path }\end{array}$ & $\begin{array}{l}\text { Pengguna memilih } \\
\text { menu diagnosa }\end{array}$ \\
\hline Invariant & - \\
\hline
\end{tabular}

Tabel 2. Deskripsi Use Case Diagram Menu Informasi

\begin{tabular}{|l|l|}
\hline $\begin{array}{l}\text { Use Case } \\
\text { Name }\end{array}$ & Informasi \\
\hline Requirment & A2 \\
\hline Goal & $\begin{array}{l}\text { Pengguna dapat melihat } \\
\text { informasi }\end{array}$ \\
\hline Pre-condition & $\begin{array}{l}\text { Pengguna memilih menu } \\
\text { utama }\end{array}$ \\
\hline Post-condition & tampil informasi \\
\hline $\begin{array}{l}\text { Failed end } \\
\text { condition }\end{array}$ & $\begin{array}{l}\text { Pengguna tidak memilih } \\
\text { menu informasi }\end{array}$ \\
\hline Primary Actor & Pengguna \\
\hline $\begin{array}{l}\text { Main } \\
\text { Flow/Basic } \\
\text { Path }\end{array}$ & $\begin{array}{l}\text { Pengguna memilih menu } \\
\text { informasi }\end{array}$ \\
\hline Invariant & - \\
\hline
\end{tabular}

Tabel 3. Deskripsi Use Case Diagram MenuTentang

\begin{tabular}{|l|l|}
\hline $\begin{array}{l}\text { Use Case } \\
\text { Name }\end{array}$ & Tentang \\
\hline Requirment & A3 \\
\hline Goal & $\begin{array}{l}\text { Pengguna dapat melihat } \\
\text { informasi mengenai versi } \\
\text { program dan nama } \\
\text { pembuatnya }\end{array}$ \\
\hline Pre-condition & $\begin{array}{l}\text { Pengguna memilih menu } \\
\text { utama }\end{array}$ \\
\hline $\begin{array}{l}\text { Post- } \\
\text { condition }\end{array}$ & $\begin{array}{l}\text { Tampil informasi mengenai } \\
\text { versi program dan nama } \\
\text { pembuatnya }\end{array}$ \\
\hline $\begin{array}{l}\text { Failed end } \\
\text { condition }\end{array}$ & $\begin{array}{l}\text { Pengguna tidak memilih } \\
\text { menu tentang }\end{array}$ \\
\hline $\begin{array}{l}\text { Primary } \\
\text { Actor }\end{array}$ & Pengguna \\
\hline $\begin{array}{l}\text { Main } \\
\text { Flow/Basic } \\
\text { Path }\end{array}$ & $\begin{array}{l}\text { Pengguna memilih menu } \\
\text { tentang }\end{array}$ \\
\hline Invariant & - \\
\hline
\end{tabular}

\section{B. Activity Diagram}

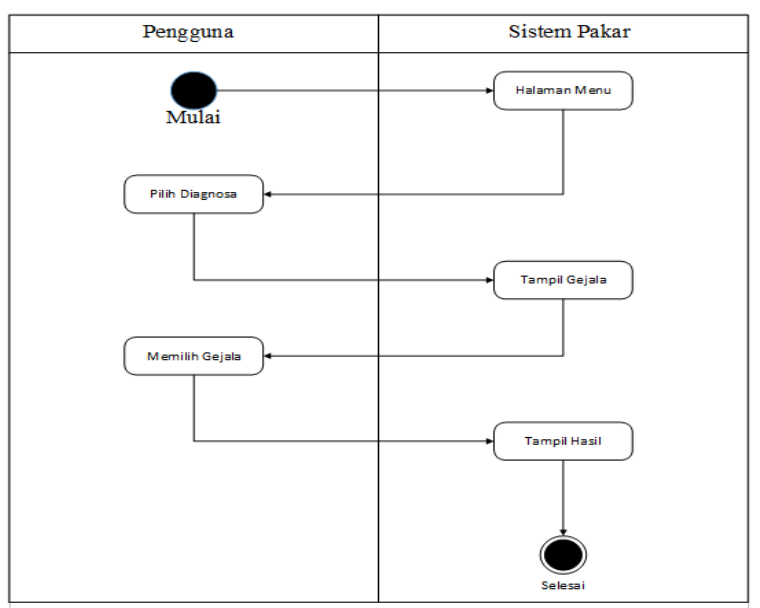




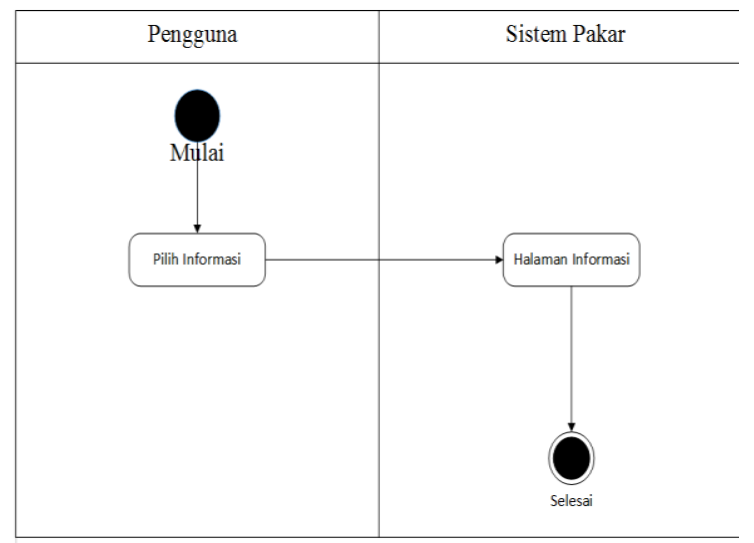

Gambar 2. Activity Diagram Menu InformasiTingkat Depresi

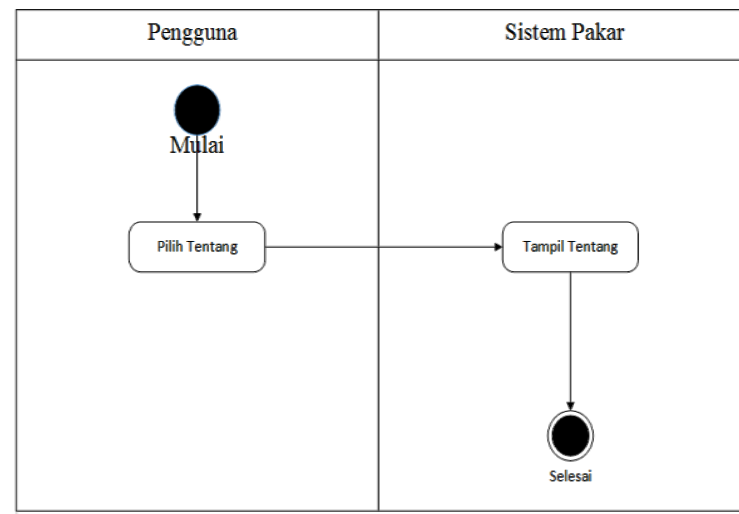

Gambar 3. Activity Diagram Menu Tentang

\section{Sequence Diagram}

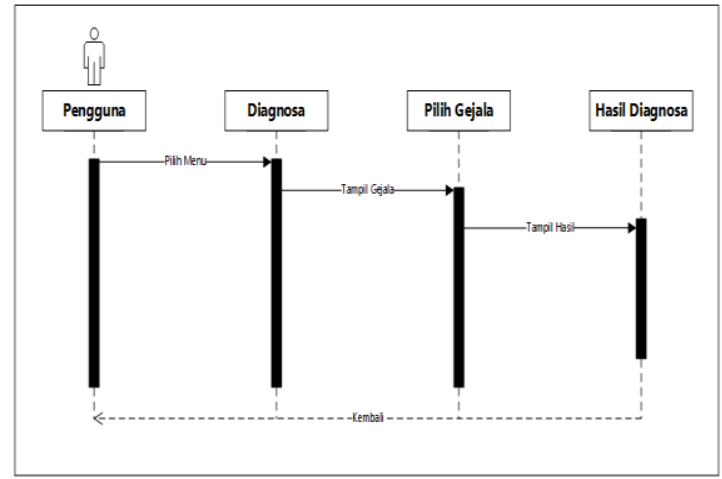

Gambar 4. Sequence Diagram Menu DiagnosaTingkat Depresi

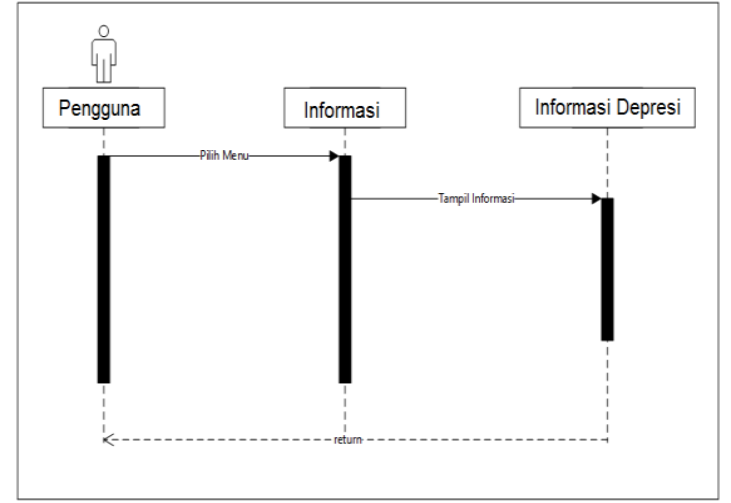

Gambar 5. Sequence Diagram Menu Informasi Tingkat Depresi

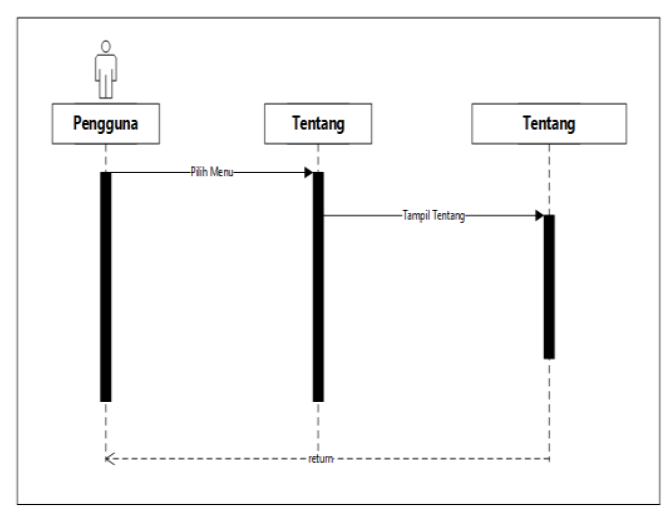

Gambar 6. Sequence Diagram Menu Tentang

D. Deployment diagram

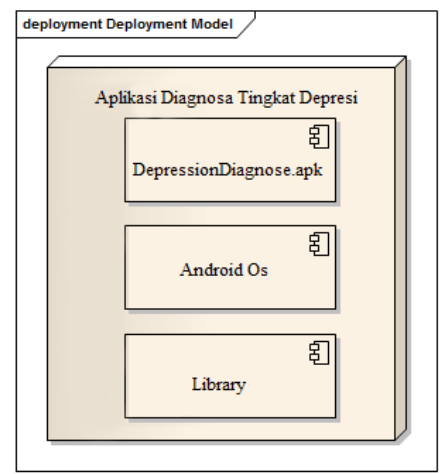

Gambar 7. Deployment Diagram DiagnosaTingkat Depresi 
User Interface

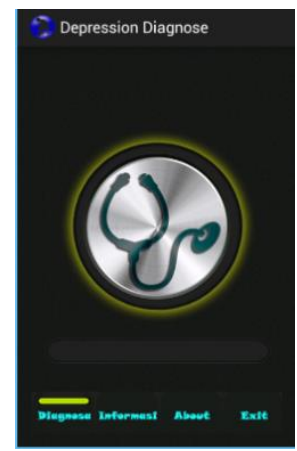

Gambar 8. Menu Utama

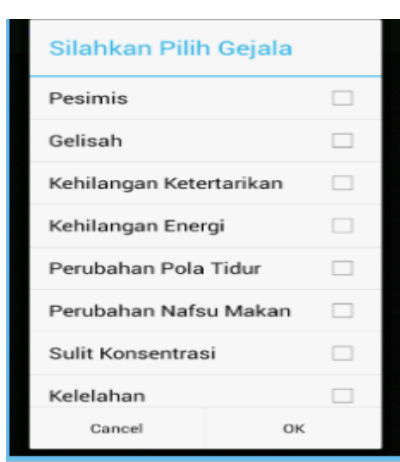

Gambar 9. Menu gejala

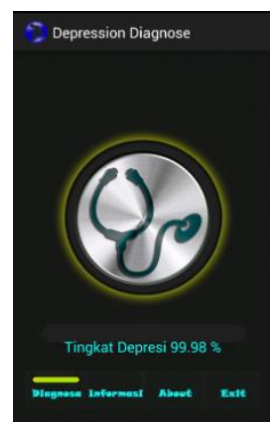

Gambar 10. Menu hasil gejala

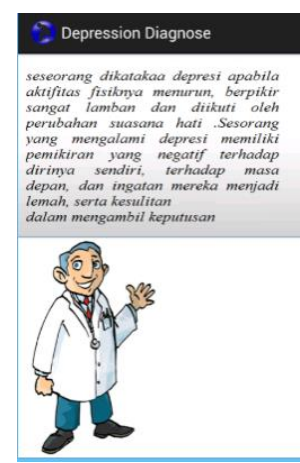

Gambar 11. Menu Informasi

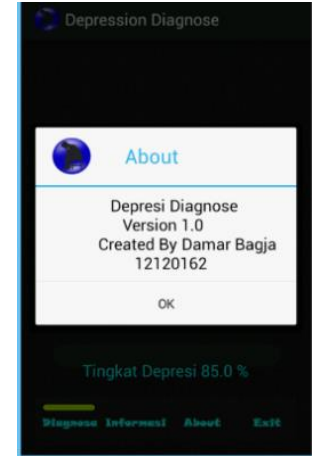

Gambar 12. Tentang

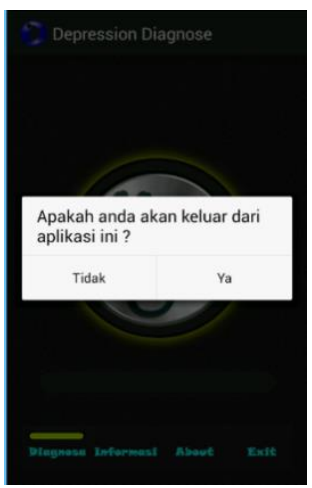

Gambar 13. Exit

\section{Kesimpulan}

Berdasarkan penelitian yang di lakukan maka dapat diambil kesimpulan bahwa Gangguan depresi merupakan masalah utama kesehatan jiwa pada mahasiswa tingkat akhir. Ini merupakan suatu hal yang penting karena orang depresi memiliki kecenderungan produktivitasnya akan menurun dan memiliki dampak yang buruk bagi mahasiswa. Untuk mengetahui tingkat depresi pada mahasiswa tingkat akhir maka dibuat aplikasi ini agar mengetahui sejauh mana tingkat depresinya dan lebih memperhatikan tingkat depresi demi pengoptimalan kesehatan. Dengan dibuat aplikasi ini agar memudahkan para pakar dalam penyampaiannya tentang pentingnya menjaga kondisi badan.

$$
\text { Penelitian ini menggunakan }
$$
menggunakan metode CF (certainty factor) sangat cocok untuk penyelesaian suatu masalah karena setiap masalah itu pasti ada faktor yang memang belum pasti hasil akhirnya. Aplikasi ini dibuat berbasis mobile agar memudahkan pengguna dan dapat diakses dimana saja. Agar aplikasi ini lebih sempurna harus memberikan informasi 
secara detail dan sebaiknya dapat di akses secara online agar dapat digunakan oleh banyak pengguna.

\section{Referensi}

Anggraini, Dini, Beni Irawan, \& Tedy Rismawan. (2014). Diagnosa Penyakit Telinga Hidung dan Tenggorokan (THT) Pada Anak Dengan Menggunakan Sistem Pakar Berbasis Mobile Android. ISSN : 2338-493x. Pontianak : Jurnal Coding Sistem Komputer Universitas Tanjungpura Vol.02 No.2 2014.

Daniel dan Virginia, G. (2010). Implementasi Sistem Pakar Untuk Mendiagnosis Penyakit Dengan Gejala Demam Menggunakan Metode Certainty Factor. Jurnal Informatika. 6, (1), 26

Kaplan, H.I \& Sadock, B.J. (1996). Pocket Handbook of Clinical Psychiatry. Baltimore : Williams and Wilkins.

Lubis, Namora Lumongga. (2009). Depresi Tinjauan Psikologis. Jakarta: Kencana Prenada media Group

Muhardi, Dedi. (2014). Sistem Pakar Menentukan Tingkat Depresi Mahasiswa Semester Akhir Menggunakan Metode Certainty Factor, Pelita Informatika Budi Darma, Volume : VI, Nomor: 3, April 2014

Putra, I Putu Eka Pramana. (2016). Gambaran Tingkat Depresi Dan Obesitas Pada Mahasiswa Fakultas Kedokteran Angkatan 2013 Universitas Warmadewa Denpasar Bali, ISSN: 2303-1395 E-JURNAL MEDIKA, VOL. 5 No 5.

Sari, Weni Wilda. (2013). Perancangan Sistem Pakar Untuk Mengetahui Infertilitas Pada Perempuan Menggunakan Metode Certainty Factor. ISSN : 2301-9425. Medan : Pelita Informatika Budi Darma Vol.V No.1 November 2013.

Seligman, M.E.P. (1993). What You Can Change : The Complete Guide to Successful Self-Improvement. New York : Fawcett Columbine.
Turban, E., dan Aronson, J.E. (2001). Decision Support System and Intelligent System, 6th Edition. New Jersey: Prentice Hall International Edition.

Untari, T.D. (2005). Faktor-Faktor Yang Berhubungan Dengan Terjadinya Depresi Pada Mahasiswa Tingkat Akhir Fakultas Kesehatan Masyarakat Universitas Diponegoro Semarang Tahun 2005. Universitas Diponegoro : Tesis.

Veradani, Oksi. (2014). Sistem Pakar Untuk Mendiagnosa Baby Blues Pada Wanita Dalam Masa Nifas Dengan Menerapkan Metode Certainty Factor. ISSN : 2301-9425. Medan : Pelita Informatika Budi Darma Vol.VII No.3 Agustus 2014. 